\title{
Liquid jet breakup regimes at supercritical pressures
}

\author{
Rainer N. Dahms ${ }^{\star}$ and Joseph C. Oefelein \\ Combustion Research Facility, Sandia National Laboratories, Livermore, CA 94551, USA
}

\begin{abstract}
Previously, a theory has been presented that explains how discrete vapor-liquid interfaces become diminished at certain high-pressure conditions in a manner that leads to well known qualitative trends observed from imaging in a variety of experiments. Rather than surface tension forces, transport processes can dominate over relevant ranges of conditions. In this paper, this framework is now generalized to treat a wide range of fuel-oxidizer combinations in a manner consistent with theories of capillary flows and extended corresponding states theory. Different flow conditions and species-specific molecular properties are shown to produce distinct variations of interfacial structures and local free molecular paths. These variations are shown to occur over the operating ranges in a variety of propulsion and power systems. Despite these variations, the generalized analysis reveals that the envelope of flow conditions at which the transition from classical sprays to diffusion-dominated mixing occurs exhibits a characteristic shape for all liquid-gas combinations. For alkane-oxidizer mixtures, it explains that these conditions shift to higher pressure flow conditions with increasing carbon number and demonstrates that, instead of widely assumed classical spray atomization, diffusion-dominated mixing may occur under relevant high-pressure conditions in many modern devices.

Keywords: Supercritical, Multiphase, Liquid, Injection, Real-Fluid, Breakup Regimes
\end{abstract}

2010 MSC: 00-01, 99-00

${ }^{*}$ Corresponding author, Rndahms@sandia.gov, +1 (925) 294 - 6496, P.O. Box 969, MS
9051

Preprint submitted to Journal of $E^{A} T_{E} X$ Templates

June 25, 2015 


\section{Introduction}

Liquid injection of multicomponent fluids at elevated operating pressures is not well understood. Imaging from a variety of experiments have long shown that under some conditions, when the pressure of the working fluid approaches 5 or exceeds the thermodynamic critical pressure of the liquid phase, the presence of discrete two-phase flow dynamics may become diminished. Then, the characteristic processes of primary and secondary atomization, multicomponent evaporation, and liquid ligament and droplet formation do not occur. As a consequence, the widely acknowledged drop deformation and breakup regimes of two-phase flows [1, 2] do not apply anymore. Instead, the classical gas-liquid interface is replaced by a single-phase diffusion dominated dense-fluid mixing layer, which is substantially affected by non-ideal thermodynamics and transport. Such phenomena have been demonstrated to occur in various systems, such as those that involve the injection of liquid nitrogen or oxygen into environments composed of nitrogen, helium, hydrogen, or argon [3, 4, 5. Many works have served to corroborate these observations $[6,7,8,9,10,11,12,13,14$, 15, 16, 17, 18, 19, 20, 21, 22, 23, 24, 25, 26, 27, 28, 29, 30, 31, 32, 33, 34, 35, 36.

Modern theory has long lacked a first-principle explanation for the observed phenomena. In contrast to pure fluids, discrete vapor-liquid interfaces in multicomponent mixtures along with their surface tension forces do not necessarily diminish only because the thermodynamic critical pressure of the liquid phase is exceeded. In recent years, experimental evidence of substantial surface tension forces in various hydrocarbon mixtures at high pressures ( $\mathrm{p}>500$ bar) was provided in the literature [37, 38, 39]. It is generally accepted, however, that surface tension forces in multicomponent mixtures diminish once the temperature of the injected liquid phase approaches its critical value. Previous research into gasliquid interfaces during diesel engine fuel injection processes has shown, however, that those interfaces are generally not heated to their critical temperature due to the lack of enthalpy contained in the unburned ambient gases [40, 41]. 
Recent studies quantified the conditions under which a specific n-dodecane-nitrogen mixture (relevant for diesel engine fuel injection) transitions between classical spray atomization and diffusion-dominated dense-fluid mixing dynamics 42, 43, 44. It was established that the breakdown of the classical noncontinuum two-phase interface and the consequent development of dense-fluid mixing layers is initiated because the multi-component two-phase interface becomes much wider than the mean free molecular path. This showed that the transition to mixing layers occurs due to interfacial dynamics and not, as conventional wisdom had suggested, because the liquid phase has heated to supercritical temperatures where surface tension forces diminish.

40 The findings outlined above have most recently been corroborated by Manin et al. [45] by applying long-distance microscopic imaging using an ultra-fast LED source with a diffuser background behind the n-dodecane jet. When the jet is injected at lower temperatures but supercritical pressures, classical droplet and ligament stretch and breakup dynamics were observed. At the high pressure 45 and higher temperature conditions predicted by Dahms et al. 42, 43, 44, such dynamics become diminished and no droplets could be detected anymore. Furthermore, the transition from liquid to gaseous state appeared much smoother compared to observations made at lower temperature and pressure conditions. Falgout et al. [46] has also provided evidence of dense-fluid mixing layers using so ballistic imaging of the same diesel fuel injector at the same chamber conditions. A thickened turbulent n-dodecane-nitrogen mixing layer was found to evolve with a cellular structure characteristic of gas jets.

While the findings outlined above support the theory presented in previous works [42, 43, 44, 47, the consequence of these observations and implications with respect to other propulsion and power systems is not clear. Thus, the objective of this paper is to now apply the theory to gain a clearer understanding regarding the regimes present in other practical systems. This is accomplished by performing a generalized analysis over a wider range of propellant combinations (e.g., liquid-fuel-air in gas turbines and reciprocating engines, and liquid oxygen-hydrogen for cryogenic rocket applications). A series of representative 
interface profiles are calculated over a wide range of flow and mixture conditions. Substantial differences are demonstrated in species specific molecular properties, which result in distinct variations of two-phase interfacial structures and local mean free pathways. The systematic analysis leads to the derivation of a more general regime diagram for liquid jet breakup that demonstrates when classical drop atomization and breakup regimes are being replaced by diffusiondominated interfacial mixing for a range of conditions relevant in modern power and propulsion systems.

\section{Model formulation}

Details related to implementation of the theory to derive the regime diagrams of interest here is explained in detail by Dahms and Oefelein [4]. Thus, only a brief description is given here for brevity. The starting point of the model is based on the framework developed by Oefelein [48, which provides a generalized treatment of the thermodynamics and transport processes for hydrocarbon mixtures at near-critical and supercritical conditions. This scheme is combined with the theoretical framework developed by Dahms et al. 42 and Dahms and Oefelein [43, which facilitates vapor-liquid equilibrium and gas-liquid interface structure calculations to compute both surface tension forces and the local twophase interface thicknesses. Deriving the regime diagrams then involves the implementation of thermodynamics and transport properties coupled with linear gradient theory to model respective interfacial structures. Following is a description of both of these frameworks.

\section{A. Thermodynamic and Transport Properties}

The development of equations of state has evolved in recent decades from simple cubic and virial equations to Beattie-Bridgeman and Benedict-WebbRubin equations, and then to modified Benedict-Webb-Rubin and Helmholtz energy equations of state [49]. In this study, the extended corresponding states model [50, 51] is employed using a modified Benedict-Webb-Rubin $(B W R)$ equa- 
tion of state to evaluate the $p-v$ - $T$ behavior of the inherent dense multicompo-

\section{B. Vapor Liquid Equilibrium Theory}

The real-fluid model for multicomponent mixtures is applied to obtain vaporliquid equilibrium conditions. Assuming that the liquid is in thermodynamic equilibrium with its vapor, the equilibrium conditions are prescribed by the equality of temperature, pressure, and species chemical potentials between the 115

the extended corresponding states principle has been shown to provide consistently accurate results over the widest range of pressures, temperatures and mixture states, especially at saturated conditions. Having established an analytical representation for real mixture $p-v$ - $T$ behavior, thermodynamic properties are obtained in two steps. First, respective component properties are combined at a fixed temperature using the extended corresponding states methodology to obtain the mixture state at a given reference pressure. A pressure correction is then applied using departure functions of the form given by Reid et al. [52, Chap-

ter 5]. These functions are exact relations derived using Maxwell's relations (see for example VanWylen and Sonntag [53, Chapter 10]) and make full use of the real mixture $p-v$ - $T$ path dependencies dictated by the equation of state. Standard state properties are obtained using the databases developed by Gordon and McBride [54] and Kee et al. [55]. Chemical potentials and fugacity coefficients are obtained in a similar manner. Likewise, viscosity and thermal conductivity are obtained using the extended corresponding states methodologies developed by Ely and Hanley [56, 57]. Mass and thermal diffusion coefficients are obtained using the methodologies outlined by Bird et al. [58] and Hirschfelder et al. [59] in conjunction with the corresponding states methodology of Takahashi [60].

vapor and liquid phases. Then, the critical point of a multicomponent mixture can be obtained as the point where the mixture compositions of the vapor and liquid phase become equal at supercritical pressures. 


\section{Linear Gradient Theory for Gas-Liquid Interface Structures}

Gradient Theory provides a widely accepted methodology to calculate de-

the corresponding reduced temperature is set to a single value, consistent with suggestions from Zuo and Stenby [70. This method has found wide acceptance and has also been adopted here [69] even though more suitable and generalized 
methods have also been most recently proposed [72]. Using Gradient Theory,

\section{Discussion}

The theoretical framework described above is used to perform a detailed analysis of the fundamental physics of two-phase interface dynamics for a variety of mixture and flow conditions. The goal is to understand effects of speciesspecific molecular properties and to provide quantitative insights into liquid fluid diffusion-dominated mixing at elevated pressures. Using this theory, we consider the existence of two distinct physical conditions of interest. The first is the "classically assumed" situation when the gas-liquid interfacial structure (e.g., thickness) is much smaller than the molecular mean free path and thus Stokes equations are not valid. Corresponding states theory does also not apply for this condition, and instead we use phase equilibrium theory. The second condition is when the interface thickens to scales much greater than the molecular mean free path (as suggested by a Knudsen number criterion). At this condition, the interface itself becomes part of the continuum. Thus, both the Chapman-Enskog expansion procedure to the governing equations and the extended corresponding states theory for related calculations of mixture properties 
can be applied. It is important to recognize that phase equilibrium calculations do not provide insights into the spatial structure of the vapor-liquid interface. Here we have used Gradient Theory to provide these insights. Only in the case when the Knudsen number is approximately less than 0.1 (10 times thicker or more than the molecular mean free path) do we use corresponding states and the pseudo-critical values that are consistent with this theory (which are simply where the first and second partial derivatives of pressure with respect to specific volume are simultaneously zero), which is consistent with the notion that the entire mixture state is a continuum.

A select set of fuel-oxidizer combinations have been defined to bridge the fundamental analysis presented here to relevant conditions in modern propulsion and power systems such as liquid rockets, gas turbines, and reciprocating engines. The selected systems are summarized in Table 1. We analyze liquidoxygen and gaseous-hydrogen, liquid n-decane and gaseous nitrogen, and liquid iso-octane and gaseous nitrogen, respectively. Liquid oxygen and gaseous hydrogen represent the actual fuel-oxidizer combination of many liquid rocket systems. The two hydrocarbons (n-decane and iso-octane) represent logical single component alkanes to model real-world fuels as they have properties meaningful for aviation fuel and gasoline. The carbon numbers of the selected fuels represent a characteristic mean for the widely acknowledged distribution in carbon numbers in real fuels, as shown in a recent work by Edwards [74. This study also establishes a similarity in boiling range and density. For example, the density of JP-8 at 15 degrees Celsius is documented as approximately $0.795 \mathrm{~kg} / \mathrm{L}$, which is comparable to the density of decane at 15 degrees Celsius of $0.7344 \mathrm{~kg} / \mathrm{L}$. The mean of the boiling range of JP- 8 is documented as $T=420 \mathrm{~K}$, which also compares to the boiling point of decane at $T=447 \mathrm{~K}$. Critical temperatures and critical pressures are also provided in this study. They deviate more substantially from the selected pure-fluid fuel properties. Real-world fuels are complex mixtures of hydrocarbons and alcohols and their full complexity has not been considered in this study. However, a meaningful similarity exists between the selected alkane and the real-world fuels. 


\begin{tabular}{lccc} 
& Liquid Rocket & Gas Turbine & Gasoline Engine \\
& $\left(\mathrm{H}_{2}\right)$ & $\left(\mathrm{C}_{10}\right)$ & $\left(\mathrm{C}_{8}\right)$ \\
\hline Binary Mixture & $\mathrm{LO}_{2}-\mathrm{GH}_{2}$ & $\mathrm{LC}_{10}-\mathrm{GN}_{2}$ & $\mathrm{LC}_{8}-\mathrm{GN}_{2}$ \\
Pressure (bar) & $1-110$ & $1-70$ & $1-60$ \\
$\mathrm{~T}_{\text {Gas }}(\mathrm{K})$ & $100-400$ & $350-1100$ & $350-900$ \\
$\mathrm{~T}_{\text {Liquid }}(\mathrm{K})$ & 100 & 400 & 363
\end{tabular}

Table 1: Definition of the representative system of binary mixtures and flow conditions used to emulate realistic processes in advanced power and propulsion systems.

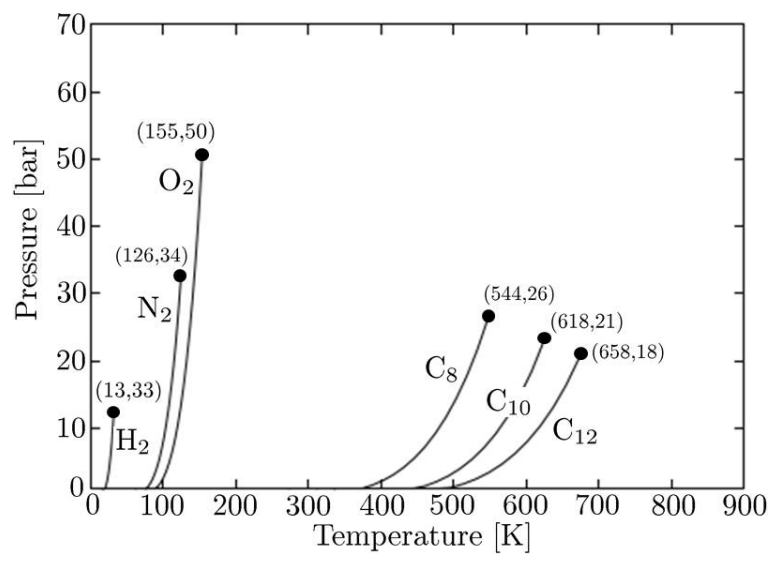

Figure 1: Saturation lines and critical points for all considered species. 
Using the selected combination of liquid propellants summarized in Table. 1 .

ing rules, thermodynamic mixture properties such as the compressibility factor, enthalpy, and fugacity coefficient are obtained. Then, vapor-liquid equilibrium conditions can be calculated. Figure 2 (top) shows envelopes of temperaturemixture compositions for a binary oxygen-hydrogen system at different pressures 235 (as one representative example). These curves illustrate that the critical temperature decreases with increasing pressure beyond the critical pressure of the liquid phase. Similarly, Fig. 2 (bottom) further highlights the maximal temperatures under which a two-phase system can be maintained as a function of pressure for all investigated mixtures. At pressures subcritical with respect to 

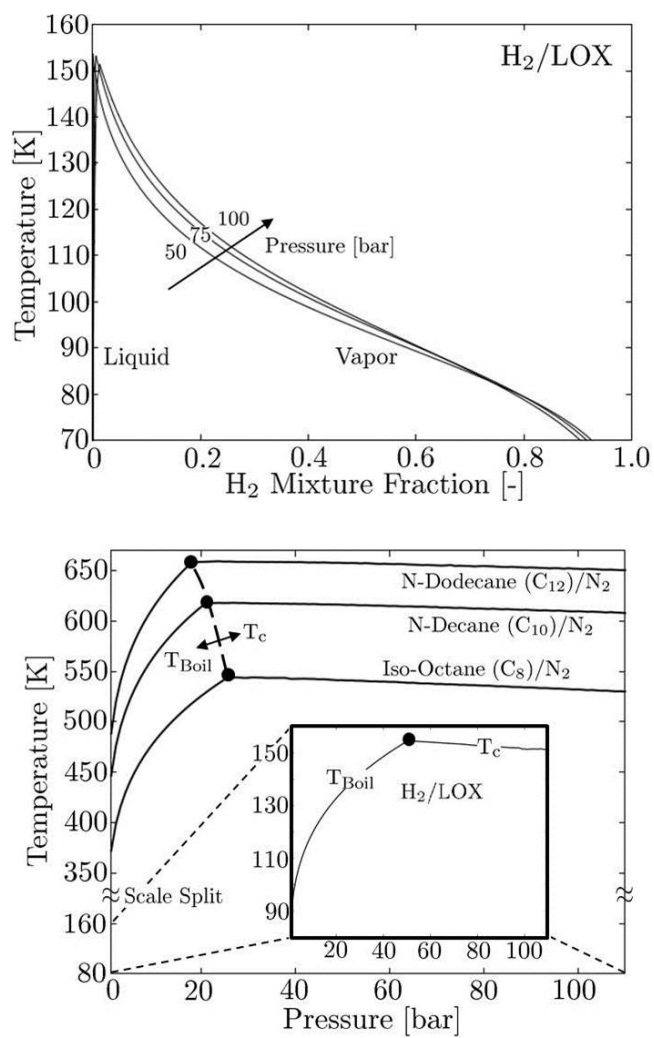

Figure 2: (Top) Vapor-liquid equilibrium conditions for an oxygen-hydrogen system at different pressures as a function of temperature and fuel $\left(\mathrm{H}_{2}\right)$ mixture fraction. (Bottom) Liquid boiling $\mathrm{T}_{\mathrm{Boil}}$ and vapor-liquid critical temperatures $\mathrm{T}_{\mathrm{C}}$ for the defined fuel-oxidizer combinations as a function of pressure. 


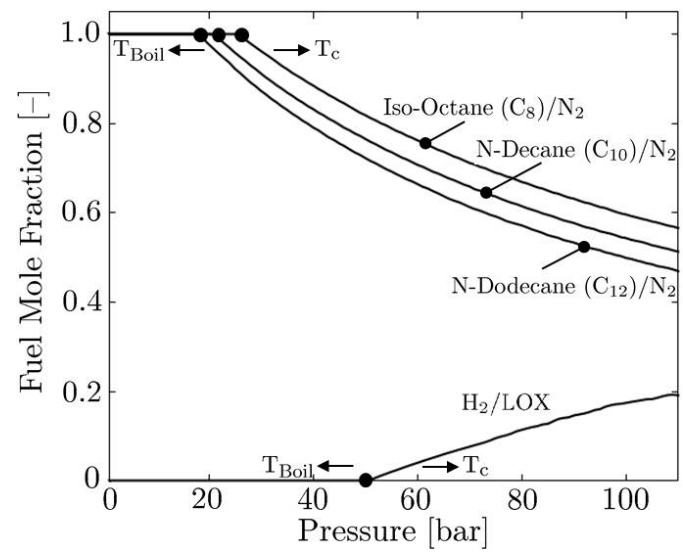

Figure 3: Fuel mole fraction at liquid phase boiling temperatures and critical mixing temperatures for subcritical and supercritical liquid phase pressures, respectively. Note that the liquid phase boiling temperature is the maximal temperature under which a two-phase system can be maintained at subcritical liquid phase pressures, compare Fig. 2(bottom).

the liquid, this temperature corresponds to the boiling temperature of the liquid phase (as shown in Fig. 1). At pressures supercritical with respect to the liquid, however, it represents the critical mixing temperature of the binary system. This critical mixing temperature decreases linearly with pressure as the gas dissolves into the liquid phase.

245 Figure 3 shows that the mole fractions of the fuel at the critical condition consistently decrease (for the hydrocarbons) and increase (for gaseous hydrogen fuel) asymptotically with pressure for all mixtures. The combination of the equation of state with vapor-liquid equilibrium calculations provide the compositions and mixture states of the respective vapor and liquid phases at given temperature and pressure conditions. To obtain information about the spatial distribution of the species compositions across the interface Linear Gradient Theory is applied. Calculations of vapor-liquid equilibrium specify the homogeneous phase vapor and liquid properties, which serve as boundary conditions in the computations. The accuracy of the method for systems considered here 255 is demonstrated in [43, 69.

Figure 4 presents the molecular mean-field density profiles within gas-liquid 

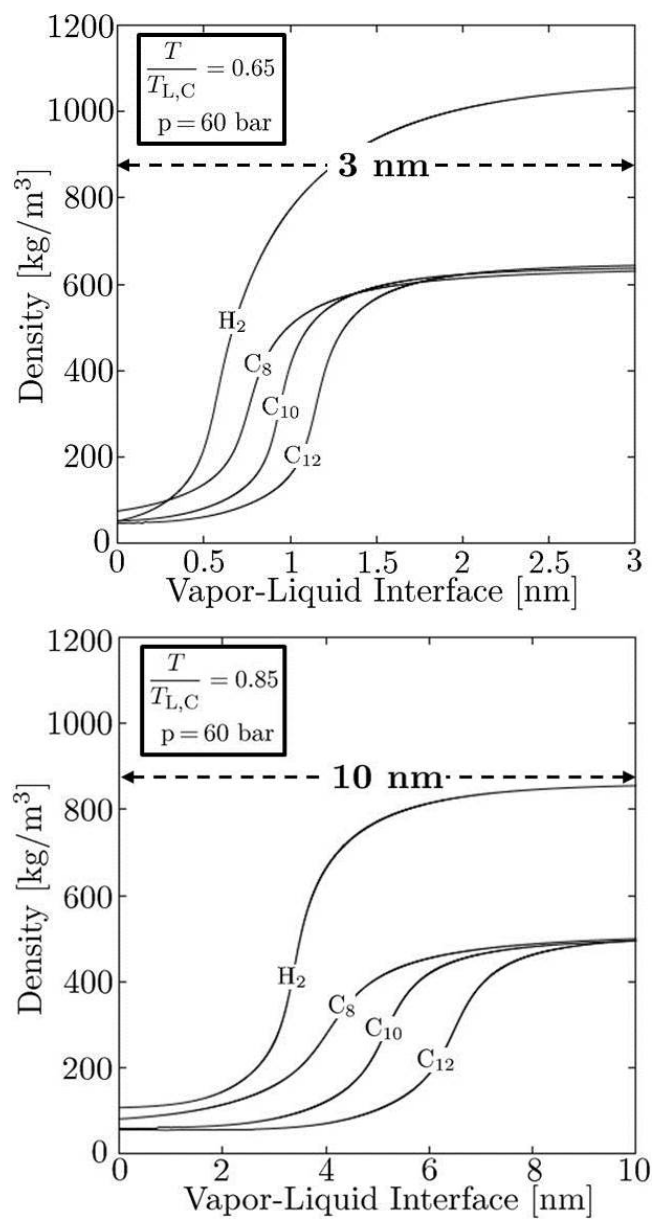

Figure 4: Molecular mean-field density profiles within two-phase interfaces for different mixtures, defined in Table 1 at constant pressure and two different reduced temperatures. 


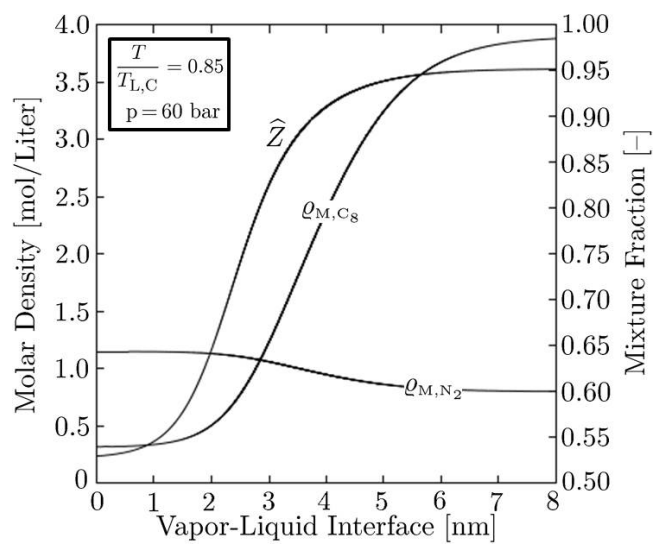

Figure 5: Mean-field molar density profiles and molecular mixture fraction distribution across the two-phase interface of a $\mathrm{C}_{8}-\mathrm{N}_{2}$ mixture at pressure $\mathrm{p}=60$ bar and reduced temperatures $\mathrm{T}_{r}=0.85$.

interfaces for different mixtures at constant pressure, supercritical with respect to all liquids, and at two different reduced temperatures. The mixtures are defined in Table 1. Consistent with vapor-liquid equilibrium and Gradient Theory assumptions, the temperature is assumed to be constant across the molecular interface. Trends in the figure show that the molecular density profiles of all mixtures have a similar hyperbolic tangent shape. The liquid density of oxygen is higher than corresponding densities of the hydrocarbon fuels. Likewise, the density ratio of the oxygen-hydrogen mixture is higher in comparison to the other systems. It is also shown that an increase in alkane carbon number results, under constant reduced temperature conditions, in a slight increase in liquid density and in the formation of thinner interfaces. With increasing temperature, as shown in Fig. 4 (bottom), the liquid densities decrease and the two-phase interface broadens substantially.

As an illustrative example, Fig. 5 shows the molecular mean-field fuel mixture fraction distribution and molar density distribution of a $\mathrm{C}_{8}-\mathrm{N}_{2}$ mixture, defined in Table 1 The molecular mixture fraction $\widehat{Z}$ is defined as

$$
\widehat{Z}=\frac{\varrho_{C_{8}}}{\varrho_{C_{8}}+\varrho_{N_{2}}}
$$




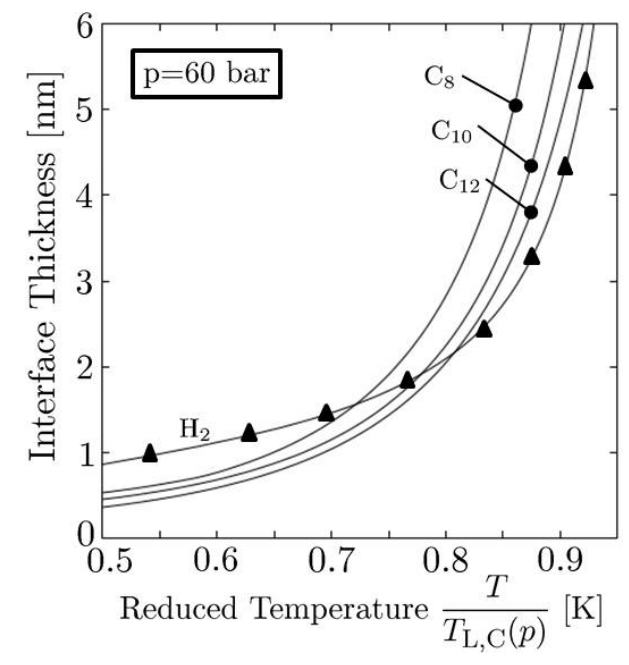

Figure 6: Representative interface thicknesses, computed using the theoretically determined criterion from Lekner and Henderson 73 for all mixtures at constant pressure as a function of the reduced temperature.

with $\varrho$ as the mean-field species mass density calculated by Gradient Theory.

The effect of temperature on the interface thickness is investigated in more detail in Fig. 6. Representative interface thicknesses, calculated using the theoretically determined criterion from Lekner and Henderson [73, are shown at constant pressure as a function of the reduced temperature. At these supercritical pressures, the critical temperature was previously shown to be a function of the pressure (see Fig. 2 (bottom). A similar exponential growth of the thickness of gas-liquid interfaces with increasing reduced temperature is consistently observed for all investigated mixtures. However, some differences exist. The required reduced temperature for a certain interface thickness increases with carbon number for alkane fuels. In combination with the likewise increase in critical temperature, compare Fig. 1. this analysis shows that higher alkane carbon number fuels are required to be heated to substantially higher subcritical temperatures in order to broaden their two-phase interfaces in equal measure.

After investigating differences in two-phase dynamics that result from variations in vapor-liquid equilibrium conditions and interfacial molecular density 


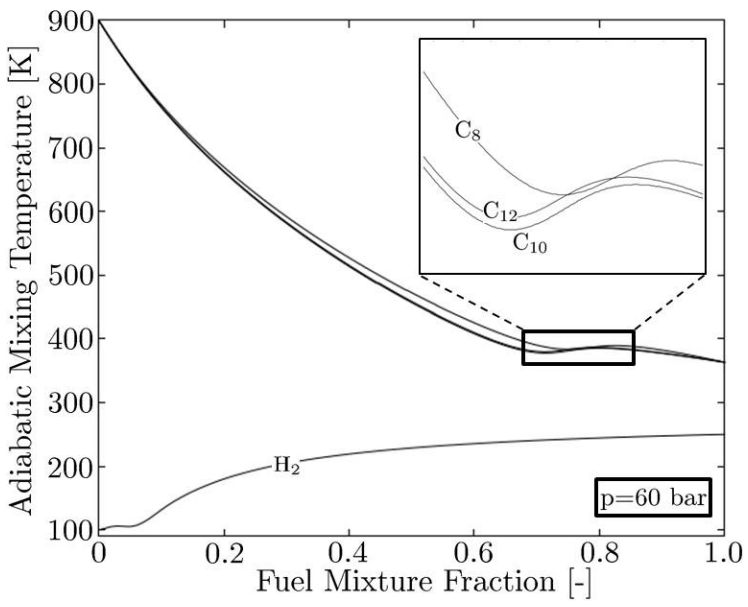

Figure 7: Adiabatic mixing temperatures of the fuel-oxidizer combinations, defined in Table 1 at constant pressure. The temperatures of the respective streams are chosen as meaningful values in corresponding power and propulsion system.

profiles due to different fuel-oxidizer combinations, single-phase mixing processes are analyzed in the following. First, a unique relationship between fuel mixture fraction and temperature is established by assuming adiabatic mixing [42, 43]. Then, the enthalpy becomes a linear function of mixture fraction. The mixture state equation is applied to obtain the adiabatic mixing temperature for each mixture fraction by matching the resulting mixture enthalpy to the prescribed enthalpy distribution. Figure 7 illustrates resulting adiabatic mixing lines for the investigated fuel-oxidizer combinations at constant pressure. Temperatures of the respective fuel and oxidizer streams have been chosen as representative values in the corresponding power and propulsion system of interest. Substantial differences in the temperature distribution exist between liquid rockets, where the oxidizer is typically injected as a liquid at about 100 $\mathrm{K}$, and gas turbines or gasoline and diesel engines, where the fuel is injected as a liquid typically at about $400 \mathrm{~K}$ and $363 \mathrm{~K}$, respectively, into a high-temperature gaseous environment. Some less significant differences among the mixing lines of the hydrocarbon-nitrogen systems are also highlighted in the inset-plot of $305 \quad$ Fig. 7 . 


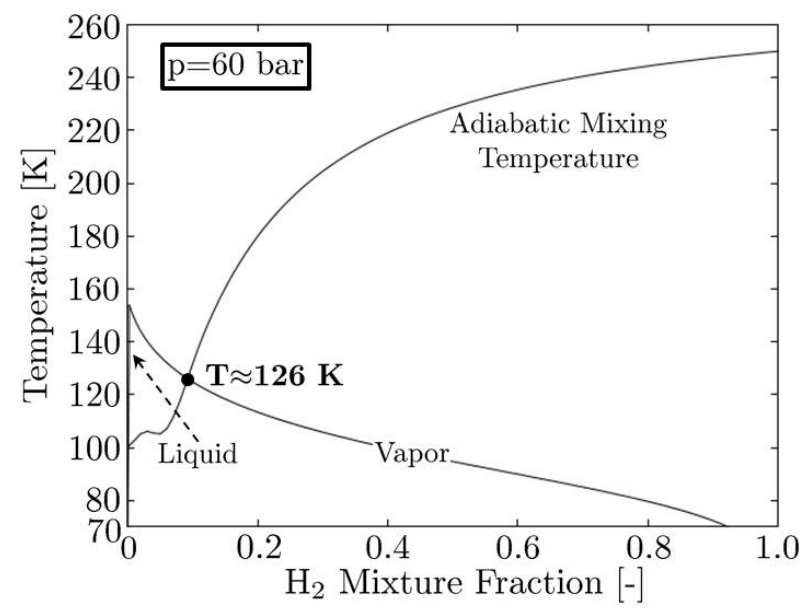

Figure 8: Illustration of a representative vapor-liquid equilibrium condition in a liquid rocket engine. This condition is restrained by the chamber pressure, which defines the envelope of possible vapor-liquid equilibrium conditions, and the adiabatic mixing line, which defines the envelope of possible vapor states.

To bridge the gap between single-phase and two-phase processes, the adiabatic mixing lines are superimposed onto the corresponding vapor-liquid equilibrium lines. The reasoning is that adiabatic mixing lines represent the envelope of conditions under which a vapor state of a two-phase vapor-liquid equilibrium condition can exist. The vapor mixes with the ambient gas and this process has to obey to the available enthalpy distribution in the system. Likewise, the chamber pressure restrains the envelope of conditions under which a vaporliquid equilibrium is possible. Figure 8 illustrates a representative vapor-liquid equilibrium condition in a liquid rocket engine. The chamber pressure and the resulting interface temperature, here $\mathrm{T} \approx 126 \mathrm{~K}$, defines the precise two-phase interface condition which is used as a boundary condition for Linear Gradient Theory to reconstruct the molecular interface structure. Then, the thickness of the interface is computed. Additionally, the mean free pathway in the vapor state has to be quantified.

320 Previously, it was shown that under some conditions the vapor mean free path can become substantially shorter than the interface thickness so that the 


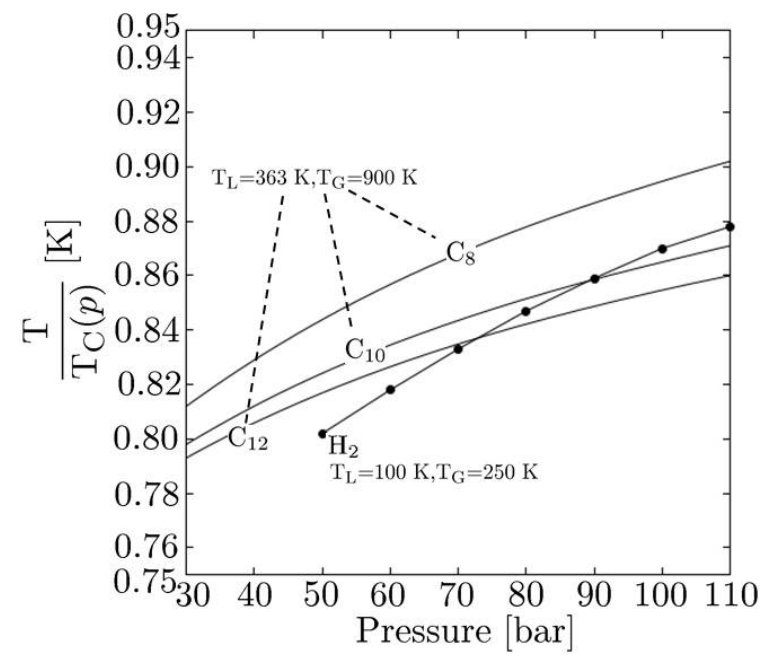

Figure 9: Reduced two-phase interface temperature as a function of pressure for the investigated fuel-oxidizer systems. Note that the critical mixing temperature $\mathrm{T}_{\mathrm{c}}$ is a function of pressure as demonstrated in Fig. 2(bottom).

two-phase interface may enter the continuum regime. Under the presence of substantial temperature gradients, the vapor does not equilibrate with the liquid anymore and the vapor-liquid equilibrium assumption becomes questionable. This condition was quantified using an interface Knudsen-number criterion [42, 43

$$
\mathrm{Kn}=\frac{\lambda_{V}}{\ell}<0.1 \rightarrow \text { Continuum Regime [75]. }
$$

Here $\lambda_{V}$ is the mean free path in the vapor, defined in 42, 43, and $\ell$ is the characteristic interface thickness.

Figure 9 shows the reduced two-phase interface temperatures as a function of pressure for the investigated fuel-oxidizer systems. This reduced temperature is defined as the ratio of the actual temperature of the interface and its critical temperature. At pressures in excess of the critical pressure of the liquid, this critical temperature decreases linearly with pressure (compare Fig. 2. bottom). The analysis shows that higher chamber pressures generally lead to 335 higher reduced interface temperatures for all mixtures. For equal chamber and injection conditions, this reduced temperature decreases with an increase of the 
fuel carbon number. Furthermore, the increase of the reduced temperature with pressure also decreases with the fuel carbon number. The curve for the liquidoxygen-gaseous hydrogen mixture starts at pressures beyond $\mathrm{p}=\mathrm{p}_{\mathrm{C}, \mathrm{O}_{2}} \approx 5.04$ $\mathrm{MPa}$, since pressures subcritical with respect to the liquid phase are not considered here.

In the following, the analysis of interface dynamics is restricted to two-phase interfaces which enter the continuum regime, verified by the Knudsen-number criterion defined in Eq. (2). Then, both the mixture fraction and the temperature are well-defined and vary continuously across the interface which evolves into a dense-fluid mixing layer. The mixture state equation can then be applied to compute the mixing layer's adiabatic mixture state conditions across the whole mixture fraction space as exemplified in Fig. 10. Assuming that the liquid $(L)$ is in thermodynamic equilibrium with its vapor $(V)$, the equilibrium conditions are prescribed by $T^{V}=T^{L}, p^{V}=p^{L}$, and $\mu_{i}^{V}=\mu_{i}^{L}$. The envelope of such vapor-liquid equilibrium conditions for a n-dodecane-nitrogen system at $\mathrm{p}=60$ bar was analyzed in detail by Dahms et al. 43, 42, 44. Results for this case are shown in Fig. 10. The interface temperature is obtained as the intersection point between the adiabatic mixing temperature and the vapor equilibrium temperature. Note that vapor-liquid equilibrium theory dictates a constant temperature across the molecular interface as highlighted in Fig. 10. Under the conditions here, however, this interfacial region enters the continuum length scale regime where it departs from such equilibrium conditions. As a consequence, adiabatic mixing temperatures are used to represent the relationship between temperature and fuel mixture fraction as illustrated in Fig. 10 .

Informed by this analysis, the equation of state can then also be used to compute the critical line of the mixture as the envelope of conditions where the temperature $T$ and pressure $p$ are equal to the critical temperature of the mixture $T_{\mathrm{C}}(\mathrm{Z})$ and critical pressure of the mixture $p_{\mathrm{C}}(\mathrm{Z})$ of the corresponding mixture state. Along this critical mixing line, the pseudo-pure fluid assumption $\left(x^{\prime}=x^{\prime \prime} ; x^{\prime}\right.$ : Liquid mole fraction; $x^{\prime \prime}$ : Vapor mole fraction) of the mixture state equation is fulfilled. Pseudo-pure fluid saturation lines for each mixture state 


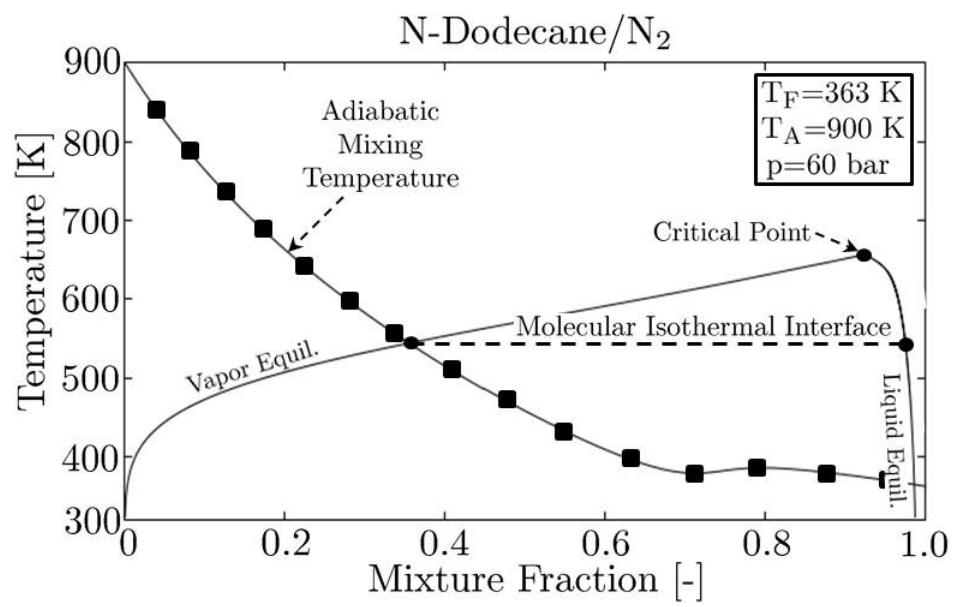

Figure 10: Adiabatic mixing line, vapor-liquid equilibrium conditions, and isothermal molecular interface line between vapor and liquid for a n-dodecane-nitrogen system at $\mathrm{p}=60 \mathrm{bar}$. $\mathrm{N}$-dodecane is injected as a liquid at $\mathrm{T}_{\mathrm{F}}=363 \mathrm{~K}$ into gaseous nitrogen at $\mathrm{T}_{\mathrm{A}}=900 \mathrm{~K}$.

are computed in a manner consistent with the extended corresponding states model.

Figure 11 shows the envelope of such saturation points for oxygen-hydrogen mixtures. The thermodynamic regimes can be defined using a pure fluid analogy. Subcritical temperatures and pressures define liquid and vapor states. Supercritical temperatures and pressures define the supercritical state. Supercritical temperatures and subcritical temperatures define an ideal gas. Supercritical pressures and subcritical temperatures define the compressed liquid phase. Pressures and temperatures are defined supercritical or subcritical for each mixture state if they are higher or lower than corresponding values of the critical line of the mixture defined in Fig. 11. This line forms the locus of critical temperatures and pressures of each mixture state in a manner consistent with corresponding states theory. They have been calculated directly from the equation of state as the points where the first and second partial derivative of the pressure with respect to the density, evaluated at constant temperature, are both zero for all 


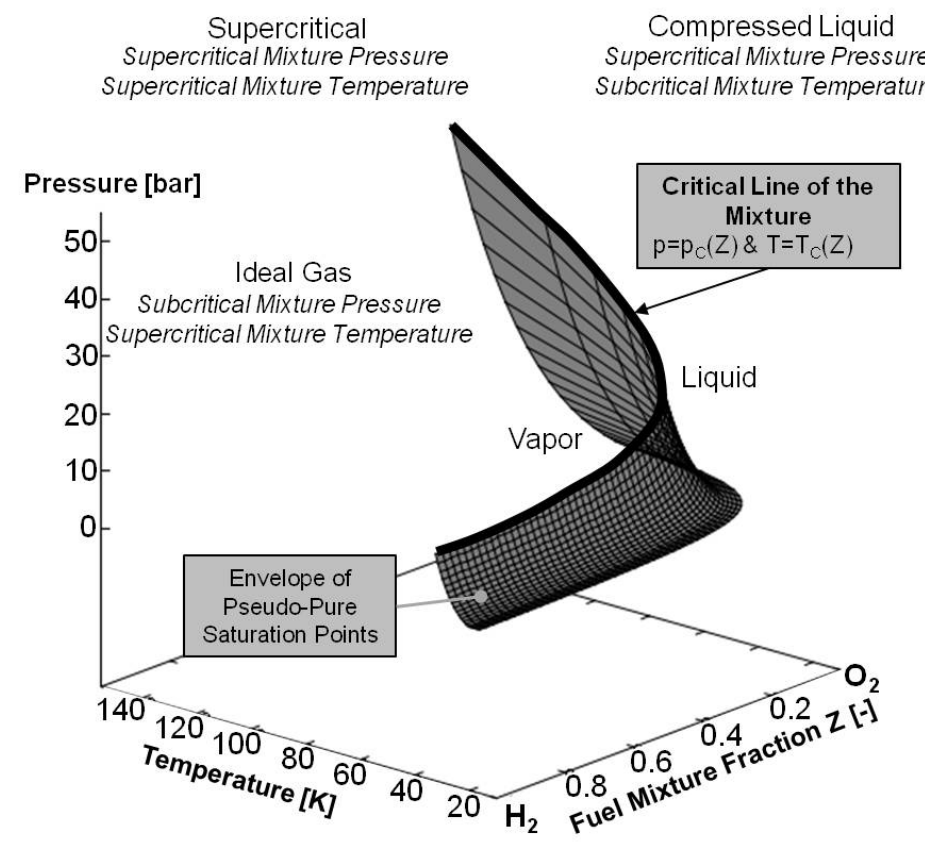

Figure 11: Pseudo-pure fluid mixture saturation surface, calculated consistent with the assumptions of the extended corresponding states theory, for oxygen-hydrogen mixtures that defines the critical line of the mixture. 
mixture states; i.e.,

$$
\left.\left(\frac{\partial p}{\partial \rho}\right)_{T}\right|_{T_{C}, \rho_{C}}=\left.\left(\frac{\partial^{2} p}{\partial \rho^{2}}\right)_{T}\right|_{T_{C}, \rho_{C}}=0
$$

It is again stressed that Eq. (3) has a physical meaning only for a multicomponent mixture in a continuum as quantified by Eq. 22. In a classical two-phase system, this state is not realizable and vapor-liquid equilibrium theory provides the appropriate method to calculate critical properties; see for example Delplanque and Sirignano [76] or Peng and Robinson [77. The critical values of the mixture according to Eq. (3) are presented in Fig. 12, The critical properties approach the corresponding pure fluid values at fuel mixture fractions $\mathrm{Z}=0$ and $\mathrm{Z}=1$, respectively. For the investigated hydrocarbon systems, the critical temperature of the mixture increases with mixture fraction. For mixture fractions lower than $\mathrm{Z} \approx 0.5$, the differences among the hydrocarbon fuels diminish. Such differences prevail, however, in the critical pressure across the whole mixture fraction space. Here, an increase in alkane carbon number fuels result in a decrease in the corresponding critical pressure of the mixture. For the oxygen-hydrogen system, the distributions of the critical values of the mixture are reversed. Both critical temperature and critical pressure of the mixture decrease with fuel mixture fraction. The conceptual picture here is in contrast to the calculation of the critical point based on vapor-liquid equilibrium, as illustrated for example in Fig. 10. Here, the critical point for the same mixture composition is calculated directly from the equation of state in a manner consistent with the assumptions of the extended corresponding states theory. This method is based on homogeneous-fluid assumptions and, as such, explicitly assumes that the two streams mix and do not form a distinct molecular interface.

Figure 13 presents the calculated reduced supercritical mixture pressure as a function of the reduced gas temperature for a specific reduced liquid injection temperature for the investigated fuel-oxidizer combinations. The reduced gas temperature is defined as the temperature of the gas that the liquid is injected into normalized by the critical temperature of the liquid phase. This figure illus- 

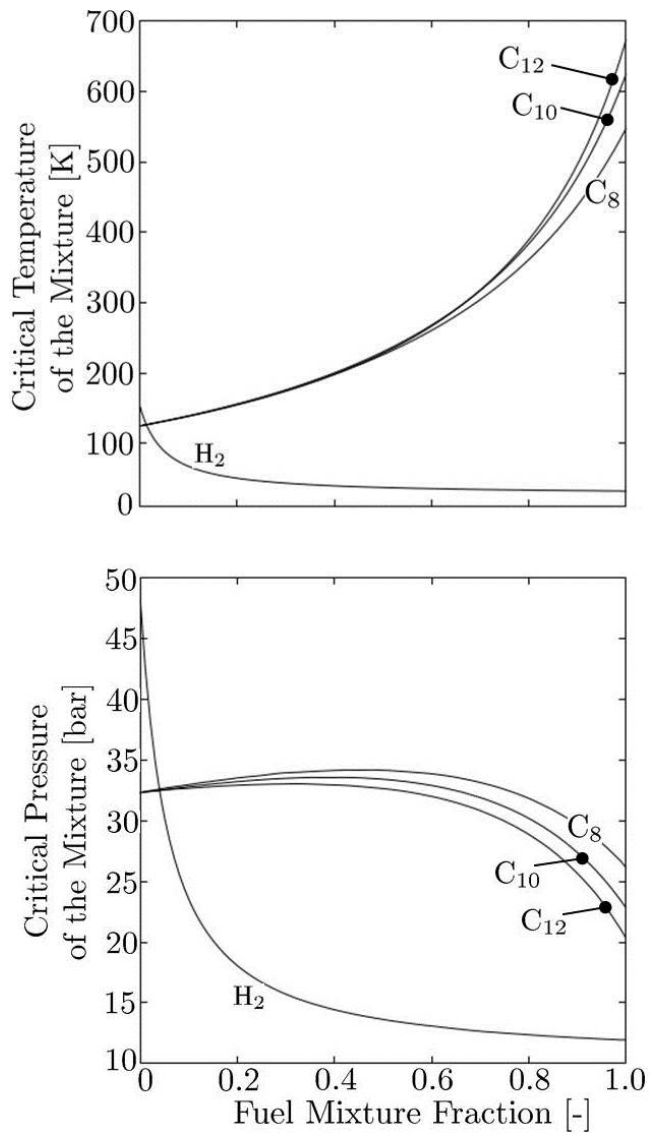

Figure 12: Critical temperature of the mixture (top) and critical pressure of the mixture (bottom) for the investigated fuel-oxidizer combinations, defined in Table 1 It is stressed that these critical values, calculated from Eq. 3, have a physical meaning only for a multicomponent mixture in a continuum as quantified by Eq. 2. In a classical two-phase system, vapor-liquid equilibrium theory provides the appropriate method to calculate critical properties 76, 77. 


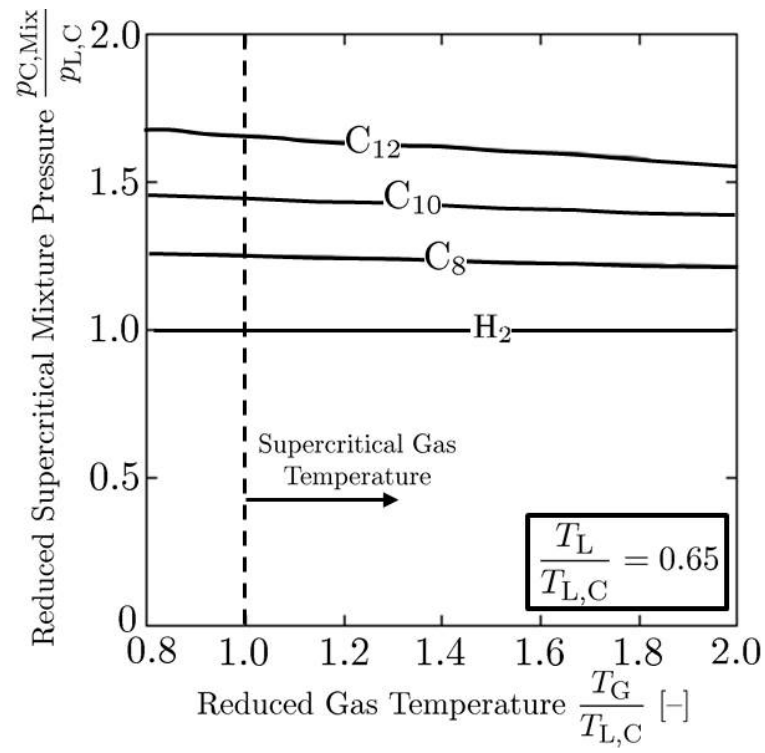

Figure 13: Reduced supercritical mixture pressure as a function of the reduced gas temperature for a certain reduced liquid injection temperature for the investigated fuel-oxidizer combinations. The supercritical mixture pressure of the oxygen-hydrogen system is constant and equal to the critical pressure of pure oxygen. Note that the application of Eq. (3) is only meaningful when the interface has entered the continuum regime at $\mathrm{Kn}<0.1$, compare Eq. 22. 


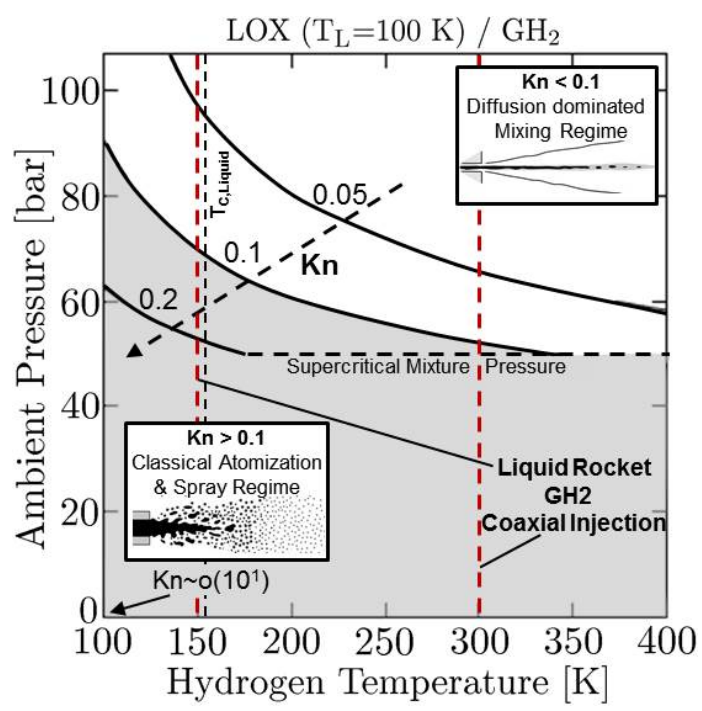

Figure 14: Spray/dense-fluid regime transitions of liquid oxygen injection at a temperature $\mathrm{T}=100 \mathrm{~K}$ along with a gaseous hydrogen coaxial injection. The range of pressures and temperatures are representative of liquid rocket operating conditions.

trates that the reduced supercritical mixture pressure increases with the alkane fuel carbon number and decreases with the reduced gas temperature. Considering the species-specific critical pressure, however, the actual pressure to support a continuous phase transition from compressed liquid to supercritical mixture states decreases with fuel carbon number. Even though the ratio $\mathrm{p}_{\mathrm{c}, \mathrm{mix}} / \mathrm{p}_{\mathrm{L}, \mathrm{c}}$ increases from the octane system $\left(\mathrm{C}_{8}\right)$ to the dodecane $\left(\mathrm{C}_{12}\right)$ system, the required chamber pressure $\mathrm{p}_{\mathrm{c}, \mathrm{mix}}$ decreases due to the much lower critical pressure $\mathrm{p}_{\mathrm{L}, \mathrm{c}}$ of $\mathrm{C}_{12}$ in comparison to $\mathrm{C}_{8}$ as highlighted in Fig.1. Interestingly, the analysis also shows that the supercritical mixture pressure of the oxygen-hydrogen system is constant and equal to the critical pressure of pure oxygen.

In the following, the conditions under which liquid jet breakup regimes of classical sprays transition to single-phase atomization of dense-fluid jets are quantified using pressure-temperature charts for each set of selected fuel-oxidizer combination. Corresponding transition conditions result from the envelope of interface Knudsen-number isolines $\mathrm{Kn}=0.1$, as defined in (2), and the super- 
critical mixture pressures, obtained from Fig. 13 Figure 14 shows such liquid jet breakup regime transitions for a range of pressures and temperatures which are representative of liquid rocket operating conditions. The considered configuration emulates a liquid oxygen injection at a temperature of $\mathrm{T}_{\mathrm{O}_{2}}=100$ $\mathrm{K}$ along with a shear-coaxial injection of gaseous hydrogen into a combustion chamber [3, 4, 78. Then, the hydrogen temperature is independent from the chamber pressure, demonstrated by the two constant hydrogen temperature injection conditions of $\mathrm{T}_{\mathrm{H}_{2}, 1}=150 \mathrm{~K}$ and $\mathrm{T}_{\mathrm{H}_{2}, 2}=300 \mathrm{~K}$ shown in Fig. 14 . Isolines of different Knudsen-numbers are presented that span a reasonable range of uncertain interface behavior [43. The regime diagram shows, consistent with observations reported by Mayer et al. [3, that classical sprays transition to dense-fluid jets at chamber pressures comparable to the critical pressure of oxygen $\left(\mathrm{p}_{\mathrm{C}, \mathrm{O}_{2}} \approx 5.04 \mathrm{MPa}\right)$ when hydrogen is coaxially injected at $\mathrm{T}_{\mathrm{H}_{2}}=300 \mathrm{~K}$. 440 It is important to realize that this conclusion has been obtained by considering the multicomponent multiphase interface dynamics. By coincidence, the analysis obtains results which are, under the conditions here, similar to those of a pure fluid analogy model for multicomponent mixtures. In pure fluids, surface tension forces diminish, independent of the temperature, when the pressure exceeds its thermodynamic critical pressure. However, as demonstrated in this paper and elsewhere [43, 42, such a pure fluid analogy is generally invalid for multicomponent mixtures.

Figure 15 presents conditions of spray/dense-fluid regime transitions of liquid injection for a range of pressures and temperatures representative of gas turbines. Liquid n-decane, an approximate single component alkane for jet-A fuel, is injected at a temperature $T_{L}=400 \mathrm{~K}$ into a pressurized nitrogen chamber. The turbine compressor increases the pressure of the ambient air before it enters the combustion chamber. Within the compressor stage, the gas undergoes a polytropic compression, which also results in an increase in gas temperature. 455 Then, the gas temperature becomes, in contrast to the liquid rocket configuration, dependent on pressure. Thus, Fig. 15 highlights relevant gas turbine compressor outlet conditions that represent characteristic pressure-temperature 


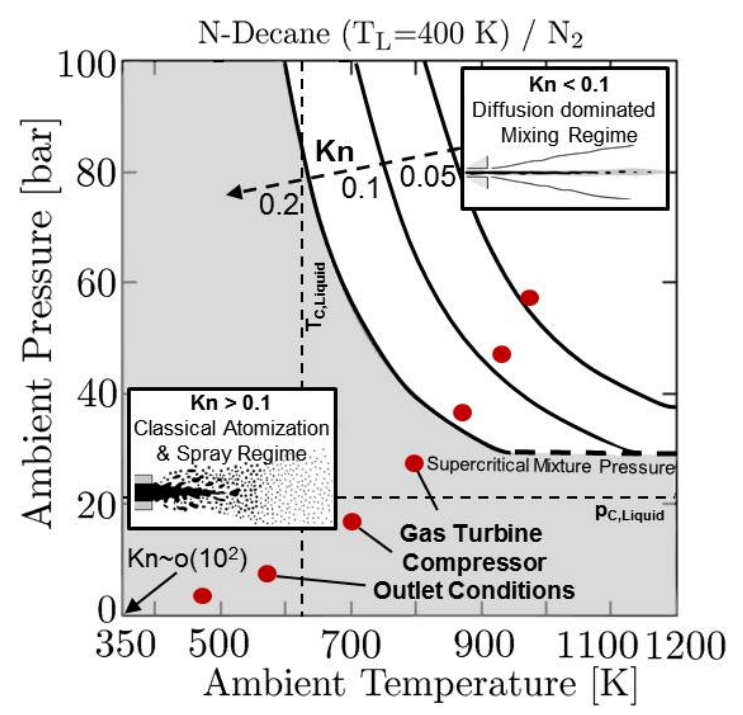

Figure 15: Spray/dense-fluid regime transitions of liquid n-decane $\left(\mathrm{C}_{10}\right)$ injection at a temperature $\mathrm{T}=400 \mathrm{~K}$ into a gaseous nitrogen environment. The range of pressures and temperatures are representative of gas turbine operating conditions.

conditions of the air entering the combustion chamber [79]. The diagram also shows isolines of meaningful interface Knudsen-number values along with the corresponding supercritical mixture pressure. Interestingly, the regime diagram suggests that, contrary to conventional wisdom, diffusion dominated mixing, instead of classical atomization and spray processes, occur at relevant highpressure ( $\mathrm{p}>35$ bar) gas turbine conditions.

Figure 16 presents conditions of spray/dense-fluid regime transitions for a range of pressures and temperatures representative of gasoline direct-injection spark-ignition engine operation. The detailed specifications of those engine operating conditions under development by engine manufacturers can be found elsewhere [14, 9, 23. In such modern gasoline engines, the fuel is injected directly into a cylinder that is usually charged with a combination of fresh air and recirculated exhaust gas. The time of fuel injection determines the pressuretemperature conditions of the ambient gas as it is being compressed due to the piston motion. This process is represented in the diagram as a polytropic com- 


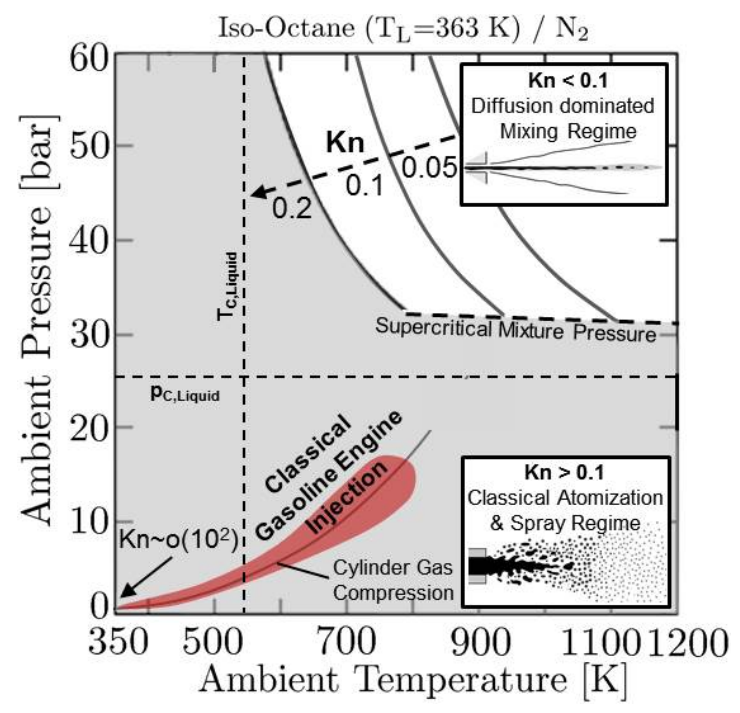

Figure 16: Spray/dense-fluid regime transitions of liquid iso-octane $\left(\mathrm{C}_{8}\right)$ injection at a temperature $\mathrm{T}=363 \mathrm{~K}$ into a gaseous nitrogen environment. The highlighted range of pressures and temperatures are representative for current gasoline direct-injection spark-ignition engine operation.

pression. Furthermore, typical cylinder gas conditions for varying spark-ignition engine operation are highlighted [23, 24, 36, 18, 80. Isolines of meaningful interface Knudsen-number values along with the supercritical mixture pressure mark the conditions where classical sprays transition to dense-fluid jets. The diagram shows that classical spray phenomena are expected to prevail under current gasoline direct-injection engine operation. Direct injection of gasoline into the combustion chamber takes place at chamber pressures substantially lower than the supercritical mixture pressure.

After investigating the spray/dense-jet transition conditions for advanced propulsion and power systems using device-specific operating conditions, Fig. 17 compares the differences associated with the various fuel-oxidizer combinations in a general manner. A diagram is derived for a specific reduced liquid injection temperature as a function of reduced gas temperature and pressure. The gas temperature is normalized by the liquid phase critical temperature. As established in Fig. 6, the two-phase interface thickness scales mainly with the reduced 


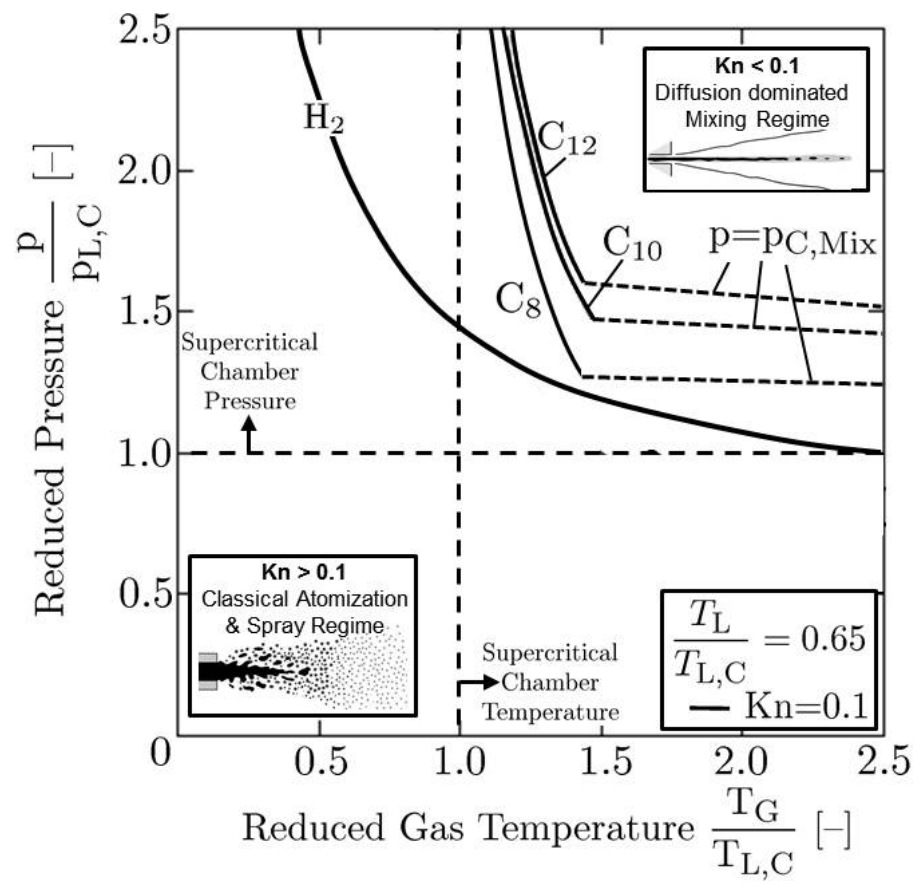

Figure 17: Spray/dense-fluid regime transition lines result from interface Knudsen-number isolines $\mathrm{Kn}=0.1$, defined in 22, and from supercritical mixture pressures, obtained from Fig. 13 The fuel-oxidizer combinations are compared for a certain reduced liquid injection temperature as a function of reduced gas temperature and pressure. 
interface temperature which depends on, at constant liquid injection conditions, the gas temperature and the liquid phase critical temperature. Both of these quantities then establish the abscissa of the liquid injection regime diagram. The diagram illustrates that the envelope of spray/dense-fluid transition conditions exhibit a similar characteristic shape for all fuel-oxidizer combinations. The precise location of the Knudsen-number isolines depends on the mixture composition and chamber pressure and shows a substantial sensitivity to the chamber temperature. At pressures just above the supercritical mixture pressure, the analysis establishes that the chamber temperature is required to exceed the critical temperature of the injected liquid phase.

Informed by this analysis, the regime diagram for liquid jet breakup at elevated pressures is introduced in Fig. 18. It is based on the same definition for the abscissa and ordinate as applied in Fig. 17. The representative spray/dense-fluid regime transition line $\overline{\mathrm{Kn}}=0.1$ is established as the average of the Knudsen-number lines shown in Fig. 17. Such an averaged location is representative and meaningful due to the similar characteristic shapes with only moderate variations of the individual species-specific isolines, demonstrated for a wide range of fuel-oxidizer combinations in Fig. 17. Then, the envelopes of typical high-pressure operating conditions in gasoline direct injection engines, gas turbines, and diesel engines are highlighted in the regime diagram. The analysis demonstrates that single-phase dense-fluid injection dynamics, instead of the widely assumed classical spray and atomization processes, may occur under many relevant high-pressure conditions in modern gas turbines and diesel engines. Classical spray atomization processes prevail in current gasoline direct injection engines. It is worth noting, however, that current trends in gasoline engine development such as downsizing and turbo-charging will likely further increase the in-cylinder pressure which may make corresponding direct injection processes also subject to dense-fluid injection dynamics.

It is essential to realize that hot unburnt gas temperatures do not, as previously demonstrated [40, 41, 42, 43, actually heat the interface to its critical value. However, supercritical temperature gas conditions lead to high subcrit- 


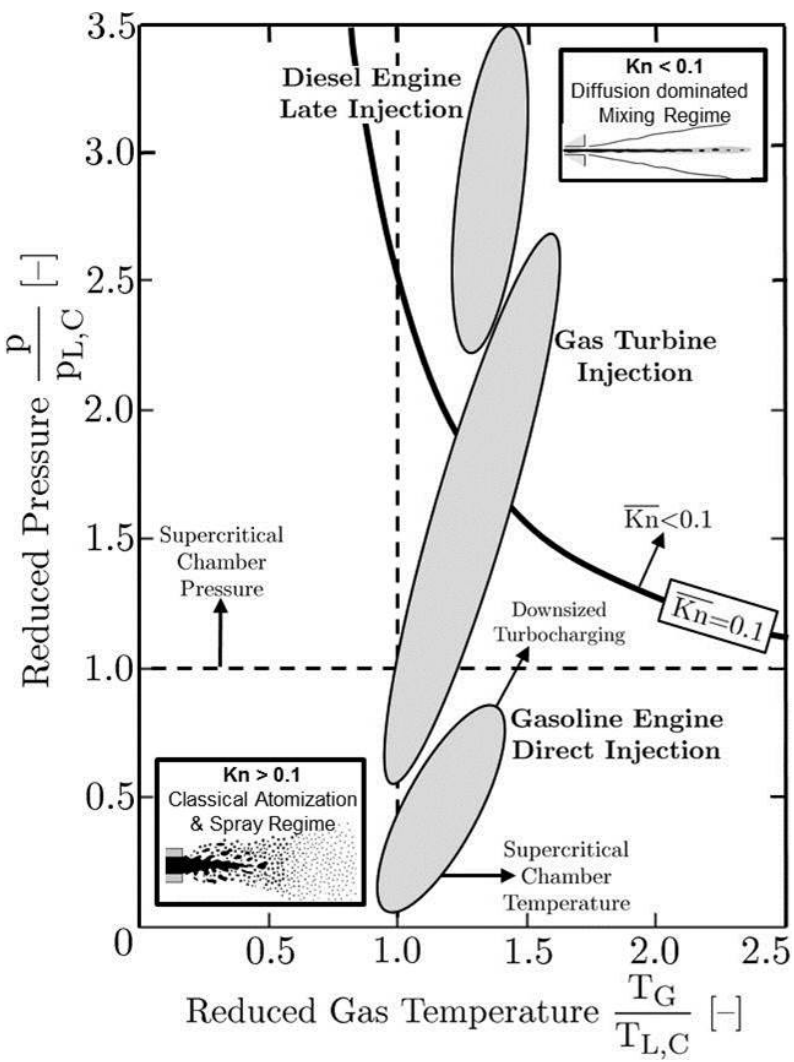

Figure 18: Regime diagram for liquid jet breakup at elevated pressures. The representative spray/dense-fluid regime transition line is obtained as an average interface $\overline{\mathrm{Kn}}=0.1$ isoline, making use of the similar characteristic envelopes of species-specific isolines as demonstrated in Fig. 17. The range of typical high-pressure operating conditions in modern power and propulsion systems is highlighted. 
ical gas-liquid interface temperatures (compare Figs. 10, 8, and 9). These are required to substantially broaden the two-phase interface (compare Fig. 6). This broadening is essential in the initiation of the transition from classical sprays to dense-fluid jets as it determines the interface Knudsen-number. With increasing pressure, however, the mean free pathway continues to shorten substantially. Then, even thinner two-phase interfaces at lower reduced subcritical temperatures, caused by cooler ambient gas, can enter the continuum regime. Hence, the required gas temperature can drop below the critical temperature of the liquid phase. As illustrated in Fig. 17, this is particularly true for the oxygen-hydrogen system. For alkane fuels, the analysis shows that the required pressure-temperature conditions for a breakdown of the two-phase interface increases with carbon number despite the simultaneous decrease in critical pressure (compare Fig. 1). Higher hydrocarbon fuels have an increasingly high density and form thinner interfaces, as shown in Fig. 4 and 6 . Hence, the required reduced interface temperature increases with the carbon number in order to compensate for this physical complexity. The simultaneous reduction in liquid phase critical pressure with carbon number which increases the reduced interface temperature (compare Fig. 2(bottom) and 9) cannot compensate for this effect. Hence, the absolute ambient gas temperature, the liquid is injected into, has to increase to maintain constant interface Knudsen numbers. This analysis then also explains why supercritical ambient gas pressure and temperature conditions with respect to the liquid phase critical properties are usually required to initiate the transition to dense-fluid mixing, even though the vapor-liquid interface does not actually reach supercritical conditions.

\section{Conclusions}

In this paper, a comprehensive analysis of liquid jet breakup regimes at elevated pressures and for different mixture and flow conditions has been presented. The analysis uses a generalized framework for multicomponent mixtures based on theories of capillary flows and extended corresponding states. It was shown 
that the multiphase interfacial structures vary substantially for different mixture and flow conditions. However, a similar exponential growth of the thickness of these interfacial structures with respect to the reduced interface temperature was consistently observed. This growth was shown to scale inversely with the pressure-dependent critical temperature of the dissolved liquid phase. In combination with substantial differences in species-specific molecule size, chemical potential, and critical properties, the analysis establishes that the proposed fundamental theory on liquid jet breakup regimes of multicomponent fluids is valid for a wide range of different fuel-oxidizer combinations.

At pressures lower than the mixture saturation limit, which quantifies the mixture-specific operating pressure to support a continuous phase transition from compressed liquid to supercritical mixture states, classical spray phenomena generally prevail. A well-defined molecular two-phase interface exists and promotes the widely acknowledged atomization, spray, and drop evaporation processes due to the presence of surface tension forces. At higher pressures, however, the two-phase interface can enter the continuum length scale regime where surface tension forces become diminished as the interfacial region substantially grows in thickness while the mean free molecular path decreases due to pressure. This consistently occurs for all investigated mixtures. Then, nearlylinear gradients over molecular distances develop within the interfacial region. Consequently, the set of vapor-liquid equilibrium assumptions along with the embedded notion of a distinct two-phase interface become questionable.

The conditions where regimes of classical drop deformation and breakup are replaced by single-phase atomization were quantified by deriving system specific regime diagrams for common liquid-gas systems. It was shown that the envelope of such transition conditions depends on molecular quantities and exhibits a characteristic shape for all selected binary mixtures. Different sets of 575 fuel-oxidizer mixtures and operating conditions were analyzed to demonstrate the significance of this theory for modern propulsion and power systems. The analysis suggests that single-phase dense-fluid injection dynamics, instead of the widely assumed classical spray and atomization processes, occur under many rel- 
evant device conditions. Then, the concept of classical spray and drop models

\section{Acknowledgement}

This research was funded by the Division of Chemical Sciences, Geosciences and Biosciences, Office of Basic Energy Sciences, US Department of Energy. Sandia National Laboratories is a multiprogram laboratory operated by Sandia Corporation, a Lockheed Martin Company, for the United States Department of Energy under contract DE-AC04-94-AL85000. This research was performed at the Combustion Research Facility, Sandia National Laboratories, Livermore, California.

\section{References}

[1] G. M. Faeth, L.-P. Hsiang, P.-K. Wu, Structure and breakup properties of sprays, Int. J. Multiphase Flow 21 (1995) 99-127. doi:10.1016/ 0301-9322(95) 00059-7. 
[2] J. C. Lasheras, E. J. Hopfinger, Liquid jet instability and atomization in a coaxial gas stream, Annu. Rev. Fluid Mech. 32 (2000) 275-308. doi: 10.1146/annurev.fluid.32.1.275

[3] W. Mayer, H. Tamura, Propellant injection in a liquid oxygen/gaseous hydrogen rocket engine., Journal of Propulsion and Power 12 (1996) 113711147. doi:10.2514/3.24154.

[4] W. Mayer, A. Schik, B. Vieille, C. Chaveau, I. Gökalp, D. Talley, R. Woodward, Atomization and breakup of cryogenic propellants under highpressure subcritical and supercritical conditions., Journal of Propulsion and Power 14 (1998) 835-842. doi:10.2514/2.5348.

[5] B. Chehroudi, D. Talley, E. Coy, Visual characteristics and initial growth rates of round crygenic jets at subcritical and supercritical pressures., Phys. Fluids 14 (2002) 850-861. doi:10.1063/1.1430735.

[6] S. Candel, M. Juniper, G. Singla, P. Scouflaire, C. Rolon, Structure and dynamics of cryogenic flames at supercritical pressure, Combust. Sci. Tech. 178 (2006) 161-192. doi:10.1080/00102200500292530

[7] L. Pons, S. Darabiha, S. Candel, G. G. Ribert, V. Yang, Mass transfer and combustion in transcritical non-premixed counterflows, Combust. Theory Modelling 2009 (2009) 57-81. doi:10.1080/13647830802368821.

[8] B. Chehroudi, Recent experimental efforts on high-pressure supercritical injection for liquid rockets and their implications, Intl. J. Aerospace Engineering 2012 (2012) 1-31. doi:10.1155/2012/121802.

[9] R. N. Dahms, C. Felsch, O. Röhl, N. Peters, Detailed chemistry flamelet modeling of mixed-mode combustion in spark-assisted HCCI engines., Proc. Combust. Inst. 33 (2011) 3023-3030. doi:10.1016/j proci.2010.08.005

[10] M. Oschwald, J. Smith, R. Branam, J. Hussong, A. Schik, B. Chehroudi, D. Talley, Injection of fluids into supercritical environments, Combust. Sci. Tech. 178 (2006) 49-100. doi:10.1080/00102200500292464. 
[11] M. Oschwald, M. M. Micci, Spreading angle and centerline variation of density of supercritical nitrogen jets, Atomization and Sprays 12 (2002) 91-106. doi:10.1615/AtomizSpr.v12.i123.50.

[12] K.-C. Lin, S. Cox-Stouffer, T. Jackson, Structures and phase transition processes of supercritical methane/ethylene mixtures injected into a subcritical environment, Combust. Sci. Tech. 178 (2006) 129-160. doi: $10.1080 / 00102200500290716$

[13] C. Felsch, R. N. Dahms, B. Glodde, S. Vogel, S. Jerzembeck, N. Peters, H. Barths, T. Sloane, N. Wermuth, A. M. Lippert, An interactively coupled cfd-multi-zone approach to model hcci combustion, Flow Turbulence Combust. 82 (2009) 621-641. doi:10.1007/s10494-009-9202-6.

[14] R. N. Dahms, T. D. Fansler, M. C. Drake, T.-W. Kuo, A. M. Lippert, N. Peters, Modeling ignition phenomena in spray-guided spark-ignited ena gines., Proc. Combust. Inst. 32 (2009) 2743-2750. doi:10.1016/j . proci. 2008.05 .052

[15] N. Zong, V. Yang, Cryogenic fluid jets and mixing layers in transcritical and supercritcal environments, Combust. Sci. Tech. 178 (2006) 193-228. doi:10.1080/00102200500287613.

[16] J. C. Oefelein, Mixing and combustion of cryogenic oxygen-hydrogen shearcoaxial jet flames at supercritical pressure, Combust. Sci. Tech. 178 (2006) 229-252. doi:10.1080/00102200500325322.

[17] J. Bellan, Theory, modeling and analysis of turbulent supercritical a mixing, Combust. Sci. Tech. 178 (2006) 253-281. doi:10.1080/ 00102200500292241

[18] R. N. Dahms, M. C. Drake, T. D. Fansler, R. O. Grover, A. S. Solomon, Detailed simulations of stratified ignition and combustion processes in a sprayguided gasoline engine using the SparkCIMM/G-equation modeling framework., SAE Int. J. Engines 5 (2012) 141-161. doi:10.4271/2012-01-0132. 
[19] L. C. Selle, N. A. Okong'o, J. Bellan, K. G. Harstad, Modelling of subgrid-scale phenomena in supercritical transitional mixing layers:

口 An a priori study, J. Fluid Mech. 593 (2007) 57-91. doi:10.1017/ S0022112007008075

[20] G. Ribert, N. Zong, V. Yang, L. Pons, N. Darabiha, S. Candel, Counterflow diffusion flames of general fluids: Oxygen/hydrogen mixtures, Combust. Flame 154 (2008) 319-330. doi:10.1016/j.combustflame.2008.04.023

[21] L. Pons, N. Darabiha, S. Candel, G. Ribert, V. Yang, Mass transfer and combustion in transcritical nonpremixed counterflows, Combust. Theory Modelling 13 (2009) 57-81. doi:10.1080/13647830802368821.

[22] T. Schmitt, Y. Méry, M. Boileau, S. Candel, Large-eddy simulation of oxygen/methane flames under transcritical conditions, Proc. Combust. Inst. 33 (2011) 1383-1390. doi:10.1016/j.proci.2010.07.036.

[23] R. N. Dahms, M. C. Drake, T. D. Fansler, T.-W. Kuo, N. Peters, Understanding ignition processes in spray-guided gasoline engines using highspeed imaging and the extended spark-ignition model SparkCIMM. Part A: Spark channel processes and the turbulent flame front propagation., Combust. Flame 158 (2011) 2229-2244. doi:10.1016/j.combustflame.2011. 03.012

[24] R. N. Dahms, M. C. Drake, T. D. Fansler, T.-W. Kuo, N. Peters, Understanding ignition processes in spray-guided gasoline engines using highspeed imaging and the extended spark-ignition model SparkCIMM. Part B: Importance of molecular fuel properties in early flame front propagation., Combust. Flame 158 (2011) 2245-2260. doi:10.1016/j.combustflame. 2011.04 .003

[25] J. Bellan, Theory, modeling and analysis of turbulent supercritical mixing, Combust. Sci. Technol. 178 (2006) 253-281. doi:10.1080/ 00102200500292241 
[28] K. Harstad, J. Bellan, Evaluation of commonly used assumptions for isolated and cluster heptane drops in nitrogen at all pressures, Combust.

[34] W. A. Sirignano, Recent advances in spray combustion theory, 44th AIAA Aerospace Sciences Meeting and Exhibitdoi:10.2514/6.2006-1522. 
[35] T. D. Fansler, D. L. Reuss, V. Sick, R. N. Dahms, Combustion instability in spray-guided stratified-charge engines: A review, Int. J. Engine Res. 16 (2015) 260-305. doi:10.1177/1468087414565675

[36] R. N. Dahms, N. Peters, D. W. Stanton, Z. Tan, J. Ewald, Pollutant formation modeling in natural gas si engines using a level set based

1. flamelet model., Int. J. Engine Res. 9 (2008) 1-14. doi:10.1243/ 14680874JER02107.

[37] O. G. Nino-Amezquita, S. Enders, P. T. Jaeger, R. Eggers, Measurement and prediction of interfacial tension of binary mixtures., Ind. Eng. Chem. Res. 49 (2010) 592-601. doi:10.1021/ie901209z

[38] S. Liu, D. Fu, J. Lu, Investigation of bulk and interfacial properties for nitrogen and light hydrocarbon binary mixtures by perturbed-chain statistical associating fluid theory combined with density-gradient theory., Ind. Eng. Chem. Res. 48 (2009) 10734-10739. doi:10.1021/ie9007437.

[39] J. Dechoz, C. Roze, Surface tension measurement of fuels and alkanes at high pressure under different atmospheres., Appl. Surf. Sci. 229 (2004) 175182. doi:10.1016/j.apsusc. 2004.01 .057 .

[40] D. L. Siebers, Liquid-phase fuel penetration in diesel sprays., SAE Paper 980809 (1998) 1-23doi:10.4271/980809.

[41] D. L. Siebers, Scaling liquid-phase fuel penetration in diesel sprays based on mixing-limited vaporization., SAE Paper 1999-01-0528 (1999) 1-26doi: 10.4271/1999-01-0528.

[42] R. N. Dahms, J. Manin, L. M. Pickett, J. C. Oefelein, Understanding highpressure gas-liquid interface phenomena in diesel engines., Proc. Combust. Inst. 34 (2013) 1667-1675. doi:10.1016/j.proci.2012.06.169.

[43] R. N. Dahms, J. C. Oefelein, On the transition between two-phase and single-phase interface dynamics in multicomponent fluids at supercritical pressures., Phys. Fluids 25 (2013) 092103-1-24. doi:10.1063/1.4820346 
[44] R. N. Dahms, J. C. Oefelein, Non-equilibrium gas-liquid interface dynamics in high-pressure liquid injection systems, Proc. Combust. Inst. 35 (2015) 1587-1594. doi:10.1016/j.proci.2014.05.155.

[45] J. Manin, M. Bardi, L. M. Pickett, R. N. Dahms, J. C. Oefelein, Microscopic investigation of the atomization and mixing processes of diesel sprays injected into high pressure and temperature environments, Fuel 134 (2014) 531-543. doi:10.1016/j.fuel.2014.05.060

[46] Z. Falgout, M. Rahm, Z. Wang, M. Linne, Evidence of supercritical mixing layers in the ECN spray A, Proc. Combust. Inst. 35 (2015) 1579-1586. doi:10.1016/j.proci.2014.06.109

[47] R. N. Dahms, J. C. Oefelein, Atomization and dense-fluid breakup regimes in liquid rocket engines, Journal of Propulsion and Power, in press doi: 10.2514/1.B35562.

[48] J. Oefelein, Large eddy simulation of turbulent combustion processes in propulsion and power systems, Progress in Aerospace Sciences 42 (2006) 2-37. doi:10.1016/j.paerosci.2006.02.001.

[49] E. W. Lemmon, R. T. Jacobsen, A new functional form and new fitting techniques for equations of state with application to pentafluoroethane

口 (HFC-125), J. Phys. Chem. Ref. Data 34 (2005) 69-108. doi:10.1063/ 1.1797813 .

[50] T. W. Leland, P. S. Chappelear, The corresponding states principle. a review of current theory and practice., Industrial and Engineering Chemistry Fundamentals 60 (1968) 15-43. doi:10.1021/ie50703a005.

[51] J. S. Rowlinson, I. D. Watson, The prediction of the thermodynamic properties of fluids and fluid mixtures-i. the principle of corresponding states and its extensions., Chem. Eng. Sci. 24 (1969) 1565-1574. doi: 10.1016/0009-2509(69)80095-3. 
[52] R. C. Reid, J. M. Prausnitz, B. E. Polling, The Properties of Liquids and Gases, McGraw-Hill, New York, 1987.

[53] G. J. VanWylen, R. E. Sonntag, Fundamentals of Classical Thermodynamics, John Wiley and Sons, Incorporated, New York, 1986.

[54] S. Gordon, B. McBride, Computer Program for Calculation of Complex Chemical Equilibrium Compositions, Rocket Performance, Incident and Reflected Shocks and Chapman-Jouguet Detonations, NASA SF-273, 1971.

[55] R. Kee, F. Rupley, J. Miller, Chemkin Thermodynamic Data Base, SAND87-8215B, 1990.

[56] J. Ely, H. Hanley, Prediction of transport properties. 1. viscosity of fluids and mixtures, Industrial and Engineering Chemistry Fundamentals 20. doi:10.1021/i100004a004.

[57] J. Ely, H. Hanley, Prediction of transport properties. 2. thermal conductivity of pure fluids and mixtures, Industrial and Engineering Chemistry Fundamentals 22. doi:10.1021/i100009a016

[58] R. Bird, W. Stewart, E. Lightfoot, Transport Phenomena, John Wiley and Sons, Incorporated, New York, 1960.

[59] J. Hirschfelder, C. F. Curtiss, R. B. Bird, Molecular Theory of Gases and Liquids, John Wiley and Sons, Incorporated, New York, 1964.

[60] S. Takahashi, Preparation of a generalized chart for the diffusion coefficients of gases at high pressures, Journal of Chemical Engineering of Japan 7 (1974) 417-420. doi:10.1252/jcej.7.417.

[61] H. Lin, Y.-Y. Duan, Q. Min, Gradient Theory modeling of surface tension for pure fluids and binary mixtures., Fluid Phase Equil. 254 (2007) 75-90. doi:10.1016/j.fluid.2007.02.013 
[62] C. Miqueu, B. Mendiboure, J. Lachaise, Modeling of the surface tension of multicomponent mixtures with the gradient theory of fluid interfaces., Ind. Eng. Chem. Res. 44 (2005) 3321-3329. doi:10.1021/ie0490861

[63] J. D. van der Waals, Square gradient model., Verhandel Konik Akad Weten Amsterdam 1 (1893) 8-15.

[64] J. S. Rowlinson, Translation of j. d. van der waals' "the thermodynamic theory of capillarity under the hypothesis of a continuous variation of density, J. Stat. Phys 20 (1979) 200-244.

[65] J. W. Cahn, J. E. Hilliard, Free energy of a nonuniform system. i. interfacial free energy., J. Chem. Phys. 28 (1958) 258-267. doi:10.1063/1.1744102

[66] E. A. Müller, A. Mejia, Interfacial properties of selected binary mixtures containing n-alkanes., Fluid Phase Equilibria 282 (2009) 68-91. doi:10. 1016/j.fluid.2009.04.022

[67] A. Mejia, J. C. Pamies, D. Duque, H. Seguara, L. F. Vega, Phase and interface behaviors and type-i and type-v lennard-jones mixtures: Theory and simulations., J. Chem. Phys. 123 (2005) 1-10. doi:10.1063/1.1955529

[68] C. Miqueu, J. M. Miguez, M. M. Pineiro, T. Lafitte, B. Mendiboure, Simultaneous application of the gradient theory and monte carlo molecular simulation for the investigation of methane/water interfacial properties., J. Phys. Chem. B 115 (2011) 9618-9625. doi:10.1021/jp202276k.

[69] K. A. G. Schmidt, G. K. Folas, B. Kvamme, Calculation of the interfacial tension of methane-water system with the linear gradient theory., Fluid Phase Equil. 261 (2007) 230-237. doi:10.1016/j.fluid.2007.07.045.

[70] Y.-X. Zuo, E. H. Stenby, A linear gradient theory model for calculating interfacial tensions of mixtures., J. Colloid Interface Sci. 182 (1996) 126132. doi:10.1006/jcis.1996.0443. 
[71] B. F. McCoy, H. T. Davis, On the free energy theory of inhomogeneous fluids., Phys. Rev. A 20 (1979) 1201-1207. doi:10.1103/PhysRevA.20. 1201.

[72] R. N. Dahms, Gradient Theory simulations of pure fluid interfaces using a generalized expression for influence parameters and a Helmholtz energy equation of state for fundamentally consistent two-phase calculations, J.

830 ㄴ Colloid Interface Sci. 445 (2015) 48-59. doi:10.1016/j.jcis.2014.12. 069.

[73] J. Lekner, J. R. Henderson, Theoretical determination of the thickness of

0 a liquid-vapour interface., Physica A 94 (1978) 545-558. doi:10.1016/ 0378-4371(78)90086-9.

835 [74] T. Edwards, Liquid fuels and propellants for aerospace propulsion: 1903-

(1 2003., Journal of Propulsion and Power 19 (2003) 1089-1107. doi:10. $2514 / 2.6946$

[75] G. A. Bird, Molecular Gas Dynamics and the Direct Simulation of Gas Flows, Oxford University Press, Incorporated, New York, 1994.

${ }_{840}$ [76] J.-P. Delplanque, W. A. Sirignano, Numerical study of the transient vaporization of an oxygen droplet at sub- and super-critical conditions, Int.

口 J. Heat Mass Tranf. 36 (1993) 303-314. doi:10.1016/0017-9310(93) 80006-G.

[77] D.-Y. Peng, D. B. Robinson, A rigorous method for predicting the critical properties of multicomponent systems from an equation of state, AIChE Journal 23 (1977) 137-144. doi:10.1002/aic.690230202.

[78] W. Mayer, A. Schik, M. Schaffler, H. Tamura, Injection and mixing processes in high-pressure liquid oxygen/gaseous hydrogen rocket combustors, Journal of Propulsion and Power 16 (2000) 823-828. doi:10.2514/2.5647.

${ }_{850}$ [79] A. H. Lefebvre, Gas Turbine Combustion, CRC Press Press, 2nd Edition, 1998. 
[80] M. C. Drake, D. C. Haworth, Advanced gasoline engine development using optical diagnostics and numerical modeling., Proc. Combust. Inst. 31 (2007)

99-124. doi:10.1016/j.proci.2006.08.120. 